\title{
CARACTERIZAÇÃO DO Tomato chlorotic spot virus ISOLADO DE JILÓ NO VALE DO PARAÍBA, ESTADO DE SÃO PAULO
}

\author{
MARCELO EIRAS ${ }^{1}$, ALEXANDRE L. R. CHAVES ${ }^{1}$, ADDOLORATA COLARICCIO ${ }^{1 *}$, RICARDO HARAKAVA ${ }^{1}$, \\ JANSEN DE ARAUJO ${ }^{1} \&$ CÉSAR M. CHAGAS ${ }^{2 *}$
}

${ }^{1}$ Centro de Sanidade Vegetal; ${ }^{2}$ Centro de Biotecnologia, Instituto Biológico de São Paulo, Av. Conselheiro Rodrigues Alves, 1252, CEP 04014-002, São Paulo, SP, e-mail: eiras@ biologico.br

(Aceito para publicação em 22/02/2002)

Autor para correspondência: Marcelo Eiras

EIRAS, M., CHAVES, A.L.R., COLARICCIO, A., HARAKAVA, R., ARAUJO, J. \& CHAGAS, C.M. Caracterização do Tomato chlorotic spot virus isolado de jiló no Vale do Paraíba, Estado de São Paulo. Fitopatologia Brasileira 27:285-291. 2002.

\section{RESUMO}

Os tospovírus são responsáveis por perdas significativas em diversas culturas, principalmente solanáceas. No município de São José dos Campos (SP), plantas de jiló (Solanum gilo) apresentando sintomas de mosaico, bolhosidades, nanismo e queda acentuada da produção foram coletadas para análise. Visando a caracterização do agente causador dos sintomas, testes biológicos, elétrono microscópicos, sorológicos e moleculares foram realizados. Através de inoculação mecânica em plantas indicadoras das famílias Amaranthaceae, Chenopodiaceae e Solanaceae obtiveram-se resultados típicos aos esperados para tospovírus. Ao microscópio eletrônico de transmissão, observaram-se, em contrastação negativa, partículas pleomórficas com diâmetro entre 80 e $110 \mathrm{~nm}$ e em cortes ultra-finos partículas presentes em vesículas do retículo endoplasmático. Através de DAS-ELISA, identificou-se o Tomato chlorotic spot virus (TCSV). A partir de RNA total extraído de folhas infetadas, amplificaram-se, via RT-PCR, fragmentos correspondentes ao gene da proteína do capsídeo ( $c p)$ os quais foram seqüenciados e comparados com outros depositados no "GenBank". A homologia de nucleotídeos e aminoácidos deduzidos foi respectivamente de 99 e $95 \%$ quando comparada com sequiências de isolados de TCSV. A comparação com as outras espécies do gênero Tospovirus apresentou valores de homologia entre 72 e 84\%. Estes resultados confirmam a identidade deste vírus como pertencente à espécie TCSV, que é predominante no Estado de São Paulo e importante patógeno de outras plantas cultivadas. Além disso, variedades de jiló quando inoculadas foram susceptíveis tanto ao TCSV como às espécies Tomato spotted wilt virus (TSWV) e Groundnut ringspot virus (GRSV).

Palavras-chave adicionais: Bunyaviridae, TCSV, Solanáceas.

\section{ABSTRACT \\ Characterization of a Tomato chlorotic spot virus isolated from gilo in Paraíba Valley, São Paulo, Brazil}

Tospoviruses are responsible for important losses in most crops, mainly Solanaceae. Gilo (Solanum gilo) plants showing mosaic, blistering, stunting and $100 \%$ production losses were collected for analysis from São José dos Campos in the State of São Paulo. Biological, electron microscopy, serological and molecular tests were carried out in order to characterize the virus isolate. The mechanical inoculation on Amaranthaceae, Solanaceae and Chenopodiaceae plants showed typical tospovirus-induced symptoms. Pleomorphic particles from 80 to $110 \mathrm{~nm}$ were observed in negatively stained preparations and in vesicles of the endoplasmic reticulum of infected cells. Tomato chlorotic spot virus (TCSV) was identified by DAS-ELISA. DNA fragments were amplified by RT-PCR, with specific primers designed to the nucleocapsid gene (N) of the main Tospovirus species, sequenced and compared with others in the GenBank. The nucleotide and amino acid deduced sequences homology was 99 and 95\%, respectively, with TCSV. Comparison with other Tospovirus species presented values between 74 and $81 \%$. These results confirmed the identity of this virus isolate as TCSV, the main tospovirus species in São Paulo that also damages other Solanaceous crops. Varieties of gilo have been inoculated showing susceptibility to TCSV, Tomato spotted wilt virus (TSWV) and Groundnut ringspot virus (GRSV).

\section{INTRODUÇÃO}

O jiló (Solanum gilo Raddi) pertence à família Solanaceae e tem sua provável origem no continente africano, sendo muito cultivado no Brasil (Pagoto, 1986). No Estado de São Paulo, as principais regiões produtoras desta hortaliça encontram-se nas Regionais Agrícolas de Campinas, São José dos Campos e Sorocaba, com destaque para os municípios de

$\overline{\text { *Bolsista do } \mathrm{CNPq}}$
Biritiba Mirim, Embu-Guaçu, Ibiúna, Mogi das Cruzes, Santo Antônio do Pinhal, São Paulo e Taubaté, com áreas cultivadas entre 25 e 1100 ha (www.cati.sp.gov.br).

Dentre as fitoviroses que se manifestam em hortaliças no Brasil, o vira-cabeça destaca-se como uma das mais importantes, podendo infetar diversas espécies olerícolas, causando sérios prejuízos que podem chegar até $100 \%$ de perdas dependendo da cultura (Colariccio et al., 2001a). O vira-cabeça é ocasionado por um complexo viral, destacandose o Tomato spotted wilt virus (TSWV) pertencente à família 
Bunyaviridae, gênero Tospovirus, que apresenta partículas esféricas ou pleomórficas com diâmetro entre 80 e 110 nm. Seu genoma é constituído por três segmentos de RNA denominados S ("small"), M ("medium") e L ("large"). O S RNA apresenta duas fases abertas de leitura - ORFs (ambisense) que codificam uma proteína não estrutural (gene $N S s$ ) e a proteína do nucleocapsídeo (gene $N$ ). O M RNA também possui duas ORFs (ambisense) que codificam a proteína de movimento (NSm) e um precursor das glicoproteínas (Gl/ $G 2$ ), e o L RNA apresenta uma única ORF (senso negativo) que codifica a polimerase viral (gene $L$ ) (Van Regenmortel et al., 2000). No Brasil, já foram relatadas as espécies TSWV, Tomato chlorotic spot virus (TCSV), Groundnut ringspot virus (GRSV), Chrysanthemum stem necrosis virus (CSNV), Zucchini lethal chlorosis virus (ZLCV) e Iris yellow spot virus (IYSV) (Resende et al., 1996, Bezerra et al., 1999, Pozzer et al., 1999). Devido à ampla gama de hospedeiras, mais de 1.050 espécies pertencentes a 92 famílias botânicas, incluindo monocotiledôneas e dicotiledôneas (Peters, 1998) e pela diversidade de tripes vetores, torna-se difícil o controle da doença (Prins \& Goldbach, 1998).

Com o objetivo de identificar o vírus causador dos sintomas de mosaico, bolhosidades, nanismo e queda de até $100 \%$ da produção, em plantas de jiló provenientes do município de São José dos Campos, testes foram realizados, sendo as metodologias e os resultados obtidos neste trabalho apresentados e discutidos a seguir.

\section{MATERIAL E MÉTODOS}

\section{Origem do isolado}

Plantas de jiló, apresentando sintomas de mosaico, bolhosidades, distorção foliar, nanismo (Figura 1) e queda acentuada da produção de até $100 \%$ foram coletadas em campo de produção comercial de hortaliças situado no município de São José dos Campos (Vale do Paraíba/SP) no início do mês de abril de 2000.

\section{Testes Biológicos}

Plantas indicadoras das espécies, Chenopodium amaranticolor Coste \& Reyn, C. quinoa Willd, pertencentes à família Chenopodiaceae, Gomphrena globosa L. (Amaranthaceae) e Datura stramonium L., Lycopersicon esculentum Mill., Nicotiana glutinosa L., N. sylvestris Spegar \& Comes, N. tabacum L. ( 'Samsun NN', 'Turkish' e 'White Burley'), Petunia hybrida Vilm., Solanum gilo L., e Solanum palinacanthum Dun., pertencentes à família Solanaceae, foram inoculadas mecanicamente, utilizando-se como fonte de inóculo folhas de jiló sintomáticas trituradas em solução de sulfito de sódio $0,5 \%$, utilizando carbureto de silício (400 mesh) como abrasivo (Colariccio et al., 2001a).

Variedades de jiló ('Bernacci', 'Branco Benedito Cardoso', 'Comprido Verde Claro' - Agroceres, 'Esmeralda' e 'Nova Odessa'), provenientes de banco de germoplasma do Departamento de Horticultura do Instituto Agronômico de Campinas (IAC), foram mantidas em casa de vegetação e inoculadas mecanicamente com o vírus isolado de jiló (Chaves et al., 2000). Essas mesmas variedades também foram inoculadas com TSWV isolado de tomateiro, proveniente de Florianópolis, SC (Colariccio et al., 2000) e GRSV isolado de pimentão (Capsicum annuum L.), proveniente de Paulínia, SP (Colariccio et al., 2001). Os inóculos foram padronizados, respeitando-se a proporção de 1:10 (p:v), sendo inoculadas duas folhas desenvolvidas por planta, com $100 \mu$ do extrato bruto previamente filtrado em gaze.

\section{Microscopia eletrônica}

Amostras foliares de $N$. glutinosa, inoculadas mecanicamente, foram processadas através da técnica de contrastação negativa com acetato de uranila $2 \%$. Para a obtenção de secções ultrafinas, fragmentos foliares de jiló, naturalmente infetados, foram fixados em glutaraldeído 2,5\%

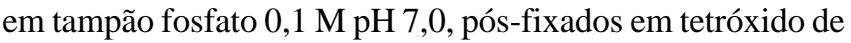
ósmio $1 \%$ no mesmo tampão, contrastados com acetato de uranila $2 \%$, desidratados em série cetônica e incluídos em "Spurr". A seguir, as secções foram contrastadas em acetato de uranila e citrato de chumbo e observadas ao microscópio eletrônico de transmissão EM-208 (Philips).

\section{DAS-ELISA}

A identificação da espécie do gênero Tospovirus presente nas amostras foi realizada através do DAS-ELISA ("double antibody sandwich - enzyme linked immunosorbent assay") utilizando anti-soros policlonais específicos contra a proteína cp (capsídeo) do TSWV, TCSV, GRSV e CSNV (De Ávila et al., 1996). As leituras de absorbância $\left(\mathrm{A}_{405} \mathrm{~nm}\right)$ foram feitas $45 \mathrm{~min}$ após a aplicação do substrato (pnitrofenilfosfato), utilizando-se o aparelho Microplate reader 3550-UV (Bio-Rad), sendo os resultados analisados pela relação da média das leituras (triplicata) das amostras infetadas, sobre a leitura das amostras sadias (I/S). Foram consideradas positivas, as amostras com leitura 3 vezes superior à média dos controles negativos.

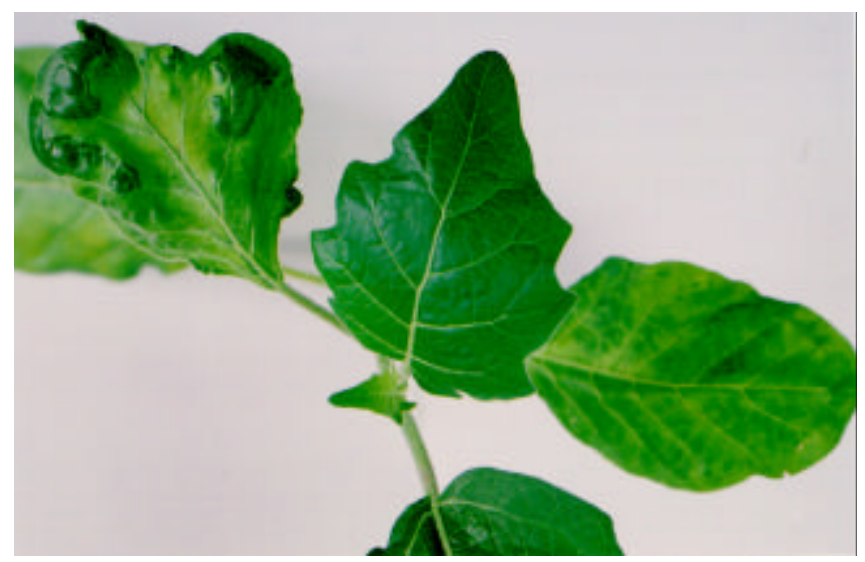

FIG. 1 - Jiló (Solanum gilo), proveniente de São José dos Campos (SP), apresentando mosaico e bolhosidades causadas pelo Tomato chlorotic spot virus (TCSV) 


\section{Extração de RNA total}

Para a extração de RNAs totais, $1 \mathrm{~g}$ de amostras foliares de D. stramonium, apresentando sintomas de mosaico e pontuações necróticas, foi submetido ao procedimento descrito por Chomczynski \& Sacchi (1987). Amostras de RNAs totais de folhas de $D$. stramonium sadias também foram extraídas para servir como controle negativo.

\section{RT-PCR}

Para a RT-PCR seguiu-se o protocolo descrito por Eiras et al. (2001a), partindo-se de $1 \mu \mathrm{g}$ de RNAs totais extraídos e utilizando-se os "primers" denominados: BR60 (5' AGAG CAATCGTGTCA 3'), desenhado para anelar na região não traduzida do terminal 3' do S RNA, do nucleotídeo 1 a 15 (senso complementar); BR65 (5' ATCAAGCCTTCTGAAAG TCAT 3'), desenhado para anelar no gene que codifica para a proteína N, do nucleotídeo 433 a 453 (senso viral); UNIV1 (5' TGTARTGRTCCATWGCA 3'), desenhado para anelar no gene que codifica para a proteína $\mathrm{N}$, do nucleotídeo 854 a 871 (senso viral) (Mumford et al., 1996). O oligonucleotídeo BR60 foi utilizado na síntese do cDNA a partir do RNA total extraído. Partiu-se de $3 \mu \mathrm{l}(1 \mu \mathrm{g})$ de RNA total $1 \mu \mathrm{l}$ do "primer" BR60 (10 ng/ $\mu \mathrm{l})$ e $6 \mu \mathrm{l}$ de água estéril, aquecidos a $70^{\circ} \mathrm{C}$ por 3 min e imediatamente colocados em gelo $\left(0^{\circ} \mathrm{C}\right)$. A seguir, adicionou-se $1 \mu \mathrm{l}$ da enzima transcriptase reversa (GibcoBRL), $1 \mu \mathrm{l}$ de dNTPs (deoxinucleotídeos), $1 \mu \mathrm{l}$ de DTT (ditiotreitol) e $4 \mu$ l de tampão da enzima ("first strand Buffer") (Gibco BRL), sendo as amostras mantidas a $37^{\circ} \mathrm{C}$ por $1 \mathrm{~h} . \mathrm{O}$ tamanho esperado para os fragmentos de DNA amplificados com os primers BR60 e UNIV1 é de 871 pares de bases (pb) e os amplificados com os primers BR60 e BR65 é de 453 pb (Figura 2). Para a PCR, foi utilizado o termociclador "Programmable Thermal Controller - PTC100" (MJ Research), e os reagentes do "kit Taq DNA Polymerase, recombinant" (Gibco BRL), seguindo as recomendações do fabricante. As condições para a PCR constaram de uma desnaturação inicial a $94{ }^{\circ} \mathrm{C}$ por $5 \mathrm{~min}$, seguida de 30 ciclos a $94{ }^{\circ} \mathrm{C}$ por $1 \mathrm{~min}, 48$ ${ }^{\circ} \mathrm{C}$ por $1 \mathrm{~min}$ e $72{ }^{\circ} \mathrm{C}$ por $1 \mathrm{~min}$, com uma extensão final de 10 min a $72{ }^{\circ} \mathrm{C}$. Os fragmentos de DNA amplificados foram visualizados em gel de agarose $1,0 \%$ corado com brometo de etídeo sob luz ultravioleta (Sambrook et al., 1989).

\section{Clonagem}

Os produtos amplificados via RT-PCR foram eluídos do gel de agarose utilizando-se o kit "Concert Rapid Gel Extraction System" (Life Technologies). Em seguida, foram ligados em pGEM-T vector (Promega) e utilizados para a transformação de células competentes de Escherichia coli (DH5- $\alpha$ ). Todos esses procedimentos seguiram as recomendações dos respectivos fabricantes e indicações contidas em Sambrook et al. (1989).

\section{Seqüenciamento}

Os produtos amplificados via RT-PCR foram seqüenciados pela técnica de reação de terminação em cadeia (Sanger et al., 1977), utilizando-se o seqüenciador automático
"ABI 377" e o "kit ABI PRISM BigDye Terminator Cycle Sequencing Ready Reaction Kit - Ampli Taq DNA Polymerase", FS (Perkin Elmer) seguindo as recomendações do fabricante. O seqüenciamento foi realizado nos dois sentidos de leitura e repetido três vezes. $\mathrm{O}$ alinhamento das seqüências obtidas foi feito com o auxílio do programa "Sequencer 3.1" (Gene Codes Corporation) e as comparações, com as seqüências existentes no banco de dados GenBank, foram feitas através do programa BLAST do National Center for Biotechnology Information (NCBI).

\section{RESULTADOS E DISCUSSÃO}

Testes biológicos, sorológicos, elétrono-microscópicos e moleculares permitiram a identificação e caracterização do agente fitopatogênico responsável pelos sintomas típicos aos induzidos por vírus em cultura de jiló no município de São José dos Campos, SP. Os resultados obtidos nos diferentes testes foram importantes para a determinação tanto do gênero quanto da espécie do fitovírus envolvido, pois, até então, no Brasil, só havia um relato da ocorrência de virose nesta cultura (Chaves et al., 2000), não tendo sido descrita, a reação de plantas de jiló quando infetadas por esse vírus.

A inoculação mecânica em plantas indicadoras induziu, em hospedeiras, sintomas típicos dos causados por espécies do gênero Tospovirus. Observaram-se lesões necróticas locais em C. amaranticolor, C. quinoa e P. hybrida e sintomas sistêmicos de anéis necróticos e mosaico em $G$. globosa, pontos necróticos e necrose em folhas de $D$. stramonium, necrose e arqueamento dos folíolos em $L$. esculentum e mosaico e necrose nas diferentes espécies de

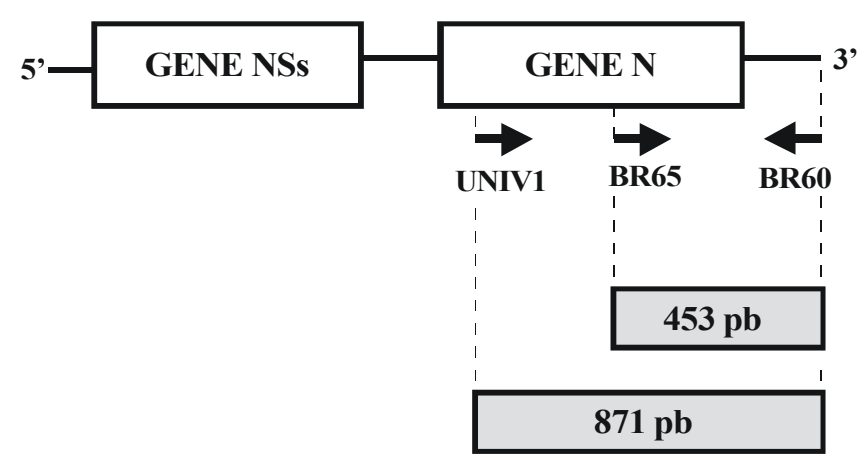

FIG. 2 - Desenho esquemático da estrutura do S RNA de Tospovirus com cerca de 2900 nucleotídeos (nt.), apresentando 2 ORFs que codificam a proteína do nucleocapsídeo $(N)$ e uma proteína não estrutural (NSs). As setas representam os oligonucleotídeos utilizados como primers denominados BR60 (senso complementar - 1 a 15 nt.), BR65 (senso viral - 433 a 453 nt.) e UNIV1 (senso viral - 858 a 871 nt.). As barras em cinza representam os tamanhos esperados para os fragmentos de DNA, amplificados via RT-PCR, de 453 e 871 pares de bases (pb) 
Nicotiana utilizadas. Plantas de S. palinacanthum, quando inoculadas com o material original infetado, desenvolveram sintomas de mosaico, distorção foliar e bolhosidades e comportaram-se como uma boa hospedeira para a manutenção do isolado in vivo, por um longo período, sem a necessidade de repicagens sucessivas. Esta característica, observada em S. palinacanthum, foi de fundamental importância para a execução dos testes biológicos subseqüentes, uma vez que a manutenção de isolados de tospovírus é fator limitante, pois, através de repicagens sucessivas, estes perdem sua infetividade e virulência (Chaves et al., 2001a).

Observações ao microscópio eletrônico de transmissão, tanto em contrastação negativa de folhas de $N$. glutinosa experimentalmente infetadas, como em cortes ultra finos de folhas de jiló naturalmente infetadas, revelaram a presença de partículas pleomórficas, com diâmetro entre 80 e 110 nm, agrupadas e envoltas por vesícula do retículo endoplasmático (Figuras 3A e B), típicas do gênero Tospovirus.

Visando a identificação da espécie de tospovírus isolado de jiló empregou-se DAS-ELISA, observando-se relacionamento sorológico somente com a espécie TCSV. A média dos valores das leituras de absorbância $\left(\mathrm{A}_{405 \mathrm{~nm}}\right)$ foi de 1,35 , sendo os valores obtidos para os demais anti-soros utilizados específicos contra a proteína $\mathrm{N}$ das espécies TSWV, GRSV e CSNV inferiores a três vezes a média das leituras do controle negativo.

Através de RT-PCR, utilizando o par de oligonucleotídeos BR60 e BR65, foram amplificados fragmentos de DNA com 453 pb (Figura 4 , linhas 2 e 4) e com o par BR60 e UNIV1, amplificaram-se fragmentos com 858 pb (Figura 4 , linhas 3 e 5). Na amostra de planta sadia não se observou nenhum produto amplificado (Figura 4, linha 6). Estes pares de oligonucleotídeos anelam no S RNA no gene que codifica a proteína do nucleocapsídeo (gene $N$ ), o que permite a amplificação de pelo menos cinco diferentes espécies de tospovírus (TSWV, TCSV, GRSV, INSV e CSNV) (Eiras et al., 2001a).

Visando a caracterização do isolado de tospovírus estudado e a confirmação dos resultados obtidos em DASELISA, os fragmentos de DNA, amplificados via RT-PCR, foram seqüenciados e as seqüências de nucleotídeos e aminoácidos deduzidos (Figura 5) foram comparadas com outras depositadas no GenBank. As maiores homologias de nucleotídeos encontradas foram de 96 e $99 \%$, respectivamente, com isolados brasileiros de TCSV, acesso no GenBank AF282982, e com o isolado denominado BR03, acesso S54325. Os maiores valores de homologia dos aminoácidos deduzidos (entre 95 e 98\%) também foram observados para os mesmos isolados, cujos números de acesso no GenBank são, respectivamente, AAG23654.1 e AAB25256.1 (Tabela 1). As comparações das seqüências de nucleotídeos e aminoácidos deduzidos do isolado de vírus de jiló com os isolados das outras espécies de tospovírus que ocorrem no Brasil, apresentaram valores de homologia inferiores a $84 \%$ (Tabela 1), estando, estes resultados, de acordo com o esperado para diferenciação de espécies de tospovírus (De Ávila et al., 1993, Pozzer et al., 1999). Através do seqüenciamento, também foi possível determinar o tamanho exato do fragmento amplificado via RT-PCR, com 858 pb. Este fragmento é ligeiramente menor do que o tamanho esperado, quando se utilizaram os oligonucleotídeos BR60 e UNIV1, conforme Mumford et al. (1996), onde obtiveram-se fragmentos com cerca de 871 pb. Essa diferença de tamanho corresponde à região não traduzida (terminal 3'), não refletindo em alteração no produto de $\mathrm{N}$.

Nos últimos anos, diferentes espécies de tospovírus têm sido identificadas e caracterizadas no Brasil (Bezerra et al., 1999, Pozzer et al., 1999). Os tospovírus estão entre os
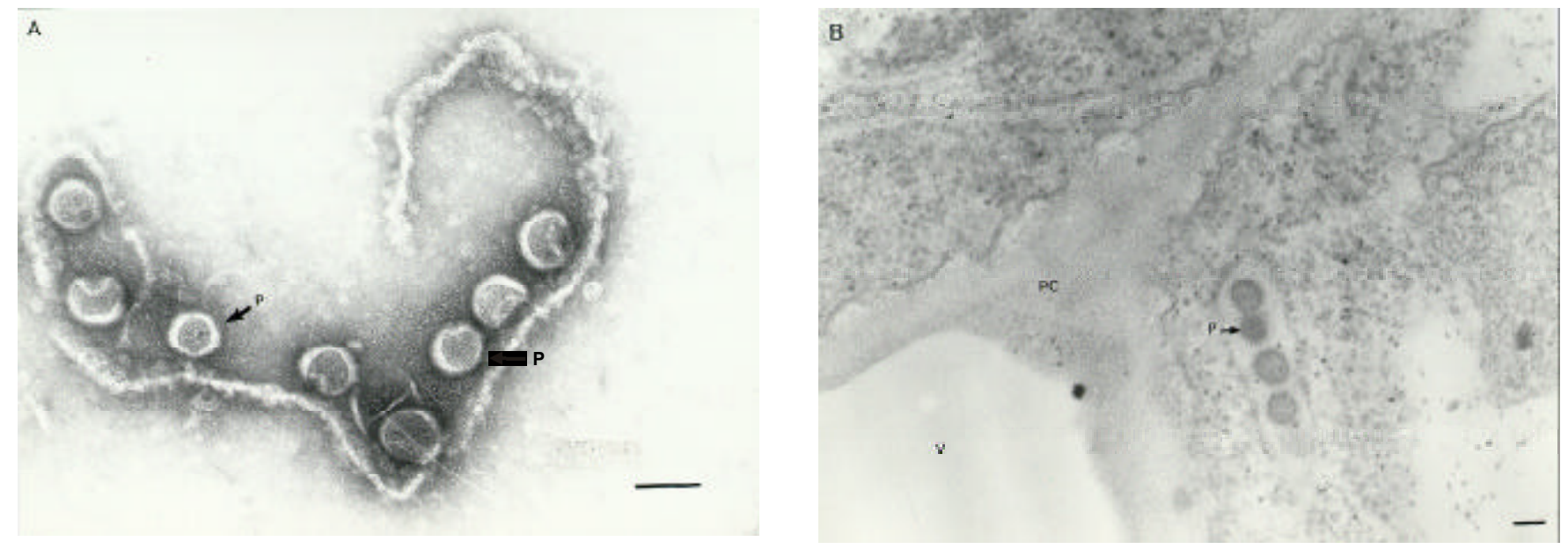

FIG. 3 - Micrografia eletrônica do Tomato chlorotic spot virus (TCSV), isolado de jiló (Solanum gilo). A. Extrato de folha de Nicotiana glutinosa, experimentalmente infetada, contrastado negativamente. Notam-se partículas contidas em presumível remanescente do retículo endoplasmático; B. Secção ultrafina de folha de jiló naturalmente infetada, mostrando partículas dentro de elemento do retículo endoplasmático. $P($ seta $=$ partículas de tospovírus; $\mathrm{V}=$ vacúolo; $\mathrm{PC}=$ parede celular. As barras representam $100 \mathrm{~nm}$ 


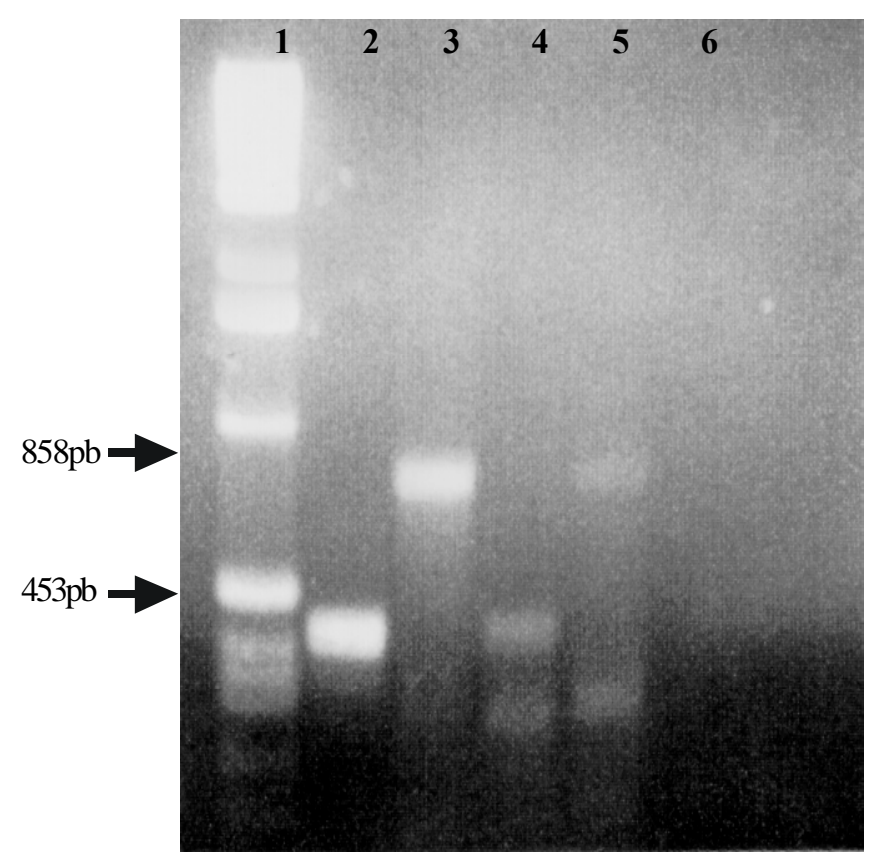

FIG. 4 - Reverse Transcriptase - Polymerase Chain Reaction (RT-PCR) para o Tomato chlorotic spot virus (TCSV), isolado de jiló (Solanum gilo) no Estado de São Paulo. As amostras 2 e 4 são fragmentos de DNA com 453 pares de bases (pb) e as amostras $3 \mathrm{e}$ 5 correspondem aos fragmentos de DNA com 858 pb amplificados via RT-PCR, respectivamente, com os primers BR60/BR65 e BR60/UNIV1, a partir de RNAs totais extraídos de planta de Datura stramonium infetada. A linha 6 representa a amostra de RNAs totais extraídos de planta sadia. A linha 1 representa o marcador de DNA 1 Kb DNA Ladder (Gibco BRL)

principais patógenos de plantas, sendo responsáveis por perdas significativas na produção, principalmente de solanáceas, em diferentes regiões produtoras localizadas no Estado de São Paulo (Colariccio et al., 2000a, 2001, 2001a), Distrito Federal e Pernambuco, mais precisamente na região do Submédio do Vale São Francisco (Lima et al., 2000). Neste trabalho, foi detectado, identificado e caracterizado um isolado do TCSV em jiló, proveniente do Vale do Paraíba, uma das principais regiões produtoras desta hortaliça no Estado de São Paulo com potencial de produção média, quando bem conduzida, de aproximadamente 24 toneladas por hectare (Pagoto, 1986).

O TCSV é predominante no Estado de São Paulo, sendo importante em diversas culturas, principalmente em hortaliças pertencentes às famílias Solanaceae e Asteraceae (Nagata et al. 1995, Colariccio et al., 2001a). Deve-se ressaltar que os municípios produtores de jiló, do Vale do Paraíba, também se destacam na produção de outras espécies de hortaliças de importância econômica como alface (Lactuca sativa L.), tomateiro e pimentão, onde já foram detectadas as espécies TCSV e GRSV ocorrendo de forma generalizada na região (Chaves et al., 2001, Colariccio et al., 2001a).

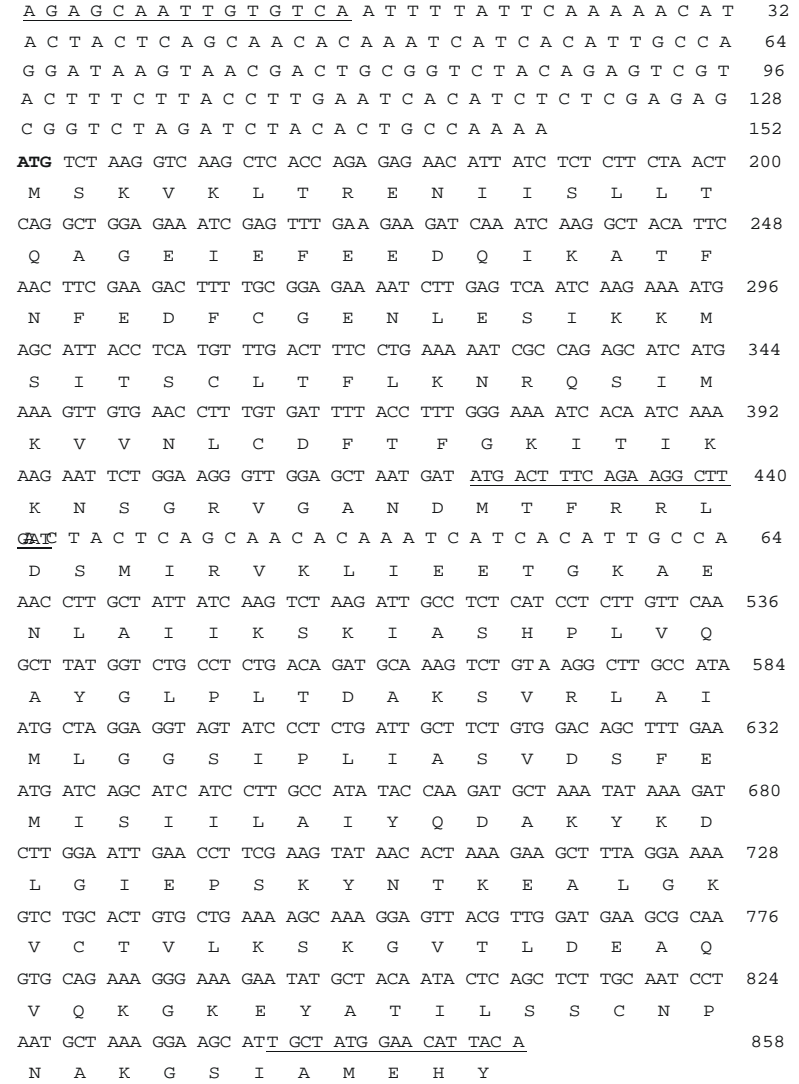

FIG. 5 - Seqüência de nucleotídeos (superior) e aminoácidos deduzidos (inferior) do fragmento de DNA (858 pb) da capa protéica do Tomato chlorotic spot virus (TCSV), isolado de jiló (Solanum gilo), amplificado via RT-PCR. Os nucleotídeos sublinhados correspondem aos oligonucleotídeos BR60 (1 a 15), BR65 (423 a 443) e UNIV1 (842 a 858). Os nucleotídeos estão numerados a partir da extremidade 5 ' da fita viral

A correta identificação e caracterização do TCSV em jiló é importante para futuros estudos, podendo contribuir para programas de melhoramento, uma vez que as cultivares disponíveis para plantio apresentam um bom nível de resistência à antracnose e murcha bacteriana. Porém, não há dados consistentes do seu comportamento com relação ao viracabeça e outras viroses, pois esta é a primeira descrição de tospovírus nesta cultura, que é exclusivamente brasileira e desconhecida nos Estados Unidos e Europa (Filgueira, 2000).

As diferentes variedades de jiló ('Bernacci', 'Branco Benedito Cardoso', 'Comprido Verde Claro' - Agroceres, 'Esmeralda' e 'Nova Odessa'), quando inoculadas mecanicamente, mostraram-se susceptíveis tanto ao TCSV isolado de jiló, como às espécies TSWV e GRSV. Estes tospovírus ocorrem de forma generalizada no Estado de São Paulo (Colariccio et al., 2001a) e passam a ser potencialmente importantes para a cultura do jiló, visto que as variedades comerciais testadas não apresentaram resistência genética a 
TABELA 1 - Comparação (homologia em porcentagem) entre as seqüências de nucleotídeos (acima da diagonal) e aminoácidos deduzidos (abaixo da diagonal, em cinza) da capa protéica do Tomato chlorotic spot virus, isolado de jiló (Solanum gilo) - TCSV-J (código de acesso AF413110, AAL07433.1) com seqüências de outros isolados de Tospovirus depositadas no Genbank*

\begin{tabular}{lccccccc}
\hline \hline Isolado & TCSV-J & TCSV $^{\mathbf{1}}$ & TCSV $^{\mathbf{2}}$ & GRSV $^{\mathbf{3}}$ & TSWV $^{\mathbf{4}}$ & $\mathbf{Z L C V}^{\mathbf{5}}$ & $\mathbf{C S N V}^{\mathbf{6}}$ \\
\hline TCSV-J & - & 99 & 96 & 81 & 78 & 74 & 73 \\
TCSV $^{\mathbf{1}}$ & 98 & - & 96 & 81 & 79 & 74 & 74 \\
TCSV $^{\mathbf{2}}$ & 95 & 96 & - & 82 & 78 & 74 & 74 \\
GRSV $^{\mathbf{3}}$ & 84 & 83 & 87 & - & 78 & 75 & 74 \\
TSWV $^{\mathbf{4}}$ & 78 & 77 & 80 & 79 & - & 74 & 76 \\
ZLCV $^{\mathbf{5}}$ & 72 & 72 & 75 & 76 & 74 & - & 77 \\
CSNV $^{\mathbf{6}}$ & 74 & 73 & 75 & 74 & 77 & 80 & - \\
\hline
\end{tabular}

1. TCSV isolado BR03 (S54325, AAB25256.1); 2. TCSV (AF282982, AAG23654.1); 3. Groundnut ringspot virus (GRSV) (AF25271, AAF64317.1); 4. Tomato spotted wilt virus (TSWV) (AB038341, BAB18308.1); 5. Zucchini lethal chlorosis virus (ZLCV) (AF067069, AAF04198.1); 6. Chrysanthemum stem necrosis virus (CSNV) (AF067068, AAF04197.1). *Os códigos de acesso no GenBank de nucleotídeos e aminoácidos estão indicados, respectivamente, entre parênteses.

estes patógenos. Vale ressaltar que o controle dos tospovírus, em jiló, é dificultado principalmente quando as plantas são infetadas no início da cultura, pois observou-se que os sintomas iniciais, arqueamento das folhas e mosaico, podem levar mais de um mês para serem perceptíveis. Isso faz com que as plantas infetadas permaneçam mais tempo no campo, servindo como fonte de inóculo e hospedeiras dos vetores, possibilitando uma maior disseminação do vírus, confirmando o que foi constatado no cultivo de jiló em São José dos Campos, com $100 \%$ de plantas infetadas (Eiras et al., 2001).

O desenvolvimento de cultivares que apresentem um bom nível de resistência a esses vírus deve ser a melhor estratégia de controle, visto que outras alternativas de controle não são viáveis como utilização de inseticidas e eliminação de plantas infetadas, uma vez que a cultura do jiló pode permanecer por um maior período de tempo no campo quando submetida a baixa temperatura (Filgueira, 2000), o que pode caracterizá-lo tanto como uma cultura mais exposta à infecção como também uma fonte de inóculo para futuras culturas suscetíveis às diversas espécies de tospovírus. Além disso, não há estudos relacionando perdas na produção dessa cultura com os aspectos epidemiológicos da doença. Estudos visando o conhecimento das relações entre as condições climáticas, as espécies de tripes vetores e a época de plantio e colheita do jiló, passam a ser considerados fundamentais para o estabelecimento de estratégias adequadas de controle dos tospovírus nesta cultura.

\section{AGRADECIMENTOS}

Os autores agradecem ao Dr. Antônio Carlos de Ávila (Embrapa-CNPH) pelos anti-soros cedidos, à Dra. Arlete M.T. Melo (IAC) pelas variedades de jiló, e ao Sr. Sérgio Vianna (IB) pelas fotografias.

\section{REFERÊNCIAS BIBLIOGRÁFICAS}

BEZERRA, I.C., RESENDE, R.O., POZZER, L., NAGATA, T., KORMELINK, R. \& DE ÁVILA, A.C. Increase of tospoviral diversity in Brazil, with the identification of two new tospovirus species, one from chrysanthemum and another from zucchini. Phytopathology 89:823-830. 1999.

CHAVES, A.L.R., EIRAS, M., COLARICCIO, A., MOREIRA, S.R. \& CHAGAS, C.M. Detecção do Groundnut ringspot virus em alface e tomateiro e do Tomato chlorotic spot virus em jiló no Estado de São Paulo. Fitopatologia Brasileira 25:439. 2000 (Resumo).

CHAVES, A.L.R., EIRAS, M., COLARICCIO, A., MOREIRA, S.R. \& CHAGAS, C.M. Detecção do Groundnut ringspot tospovirus em alface e tomateiro no Estado de São Paulo. Summa Phytopathologica 27:50-53. 2001.

CHAVES, A.L.R., MOREIRA, S.R., COLARICCIO, A. \& EIRAS, M. Preservação da infectividade de tospovírus. Summa Phytopathologica 27:115. 2001a (Resumo).

CHOMCZYNSKI, P. \& SACCHI, N. Single-step method of RNA isolation by acid guanidinium thiocyanate-phenol-chloroform extraction. Analytical Biochemistry 162:156-159. 1987.

COLARICCIO, A., CHAVES, A.L.R., EIRAS, M., CHAGAS, C.M., CASTRO, L.C., SCHROEDER, A.L. Identificação do Tomato spotted wilt tospovirus em tomateiro no Estado de Santa Catarina. Arquivos do Instituto Biológico 67:86. 2000 (Resumo).

COLARICCIO, A., CHAVES, A.L.R., EIRAS, M., CHAGAS, C.M., FRANGIONI, D.S.S. \& PAVAN, M.A. Ocorrência do Groundnut ringspot virus em pimentão no Estado de São Paulo. Summa Phytopathologica 27. 2001 (no prelo).

COLARICCIO, A., EIRAS, M., CHAVES, A.L.R., LOURENÇÃO, A.L., MELO, A.T. \& SIQUEIRA, W.J. Detecção do Chrysanthemum stem necrosis virus em tomateiro no Estado de São Paulo. Summa Phytopathologica 26:252-254. 2000a.

COLARICCIO, A., EIRAS, M., CHAVES, A.L.R., ROGGERO, P. \& CHAGAS, C.M. Diversidade de tospovírus em olerícolas no Estado de São Paulo. Summa Phytopathologica 27:177-182. 2001a.

DE ÁVILA, A.C., DE HAAN, P., KORMELINK, R., RESENDE, R.O., GOLDBACH, R.W. \& PETERS, D. Classification of tospoviruses based on phylogeny of nucleoprotein gene sequences. Journal of General Virology 74:153-159. 1993.

DE ÁVILA, A.C., LIMA, M.F., RESENDE, R.O., POZZER, L., FERRAZ, E., MARANHÃO, E.A., CANDEIA, J.A. \& COSTA, E.D. Identificação de tospovírus em hortaliças na região do sub-médio do Vale do São Francisco utilizando DAS-ELISA e dot-ELISA. Fitopatologia Brasileira 21:503-508. 1996.

EIRAS, M., CHAVES, A.L.R., COLARICCIO, A., HARAKAVA, R., ARAUJO, J. \& CHAGAS, C.M. Caracterização molecular do Tomato chlorotic spot virus isolado de jiló no Estado de São Paulo. Fitopatologia Brasileira 26:515. 2001 (Resumo).

EIRAS, M., RESENDE, R.O., MISSIAGGIA, A.A. \& DE ÁVILA, A.C. RT-PCR and dot blot hybridization methods for a universal detection of tospoviruses. Fitopatologia Brasileira 26:170-175. 2001a.

FILGUEIRA, F.A.R. Novo Manual de Olericultura: agrotecnologia moderna na produção e comercialização de hortaliças. Viçosa. Universidade Federal de Viçosa, MG, Editora UFV. 2000.

LIMA, M.F., DE ÁVILA, A.C., RESENDE, R.O. \& NAGATA, T. Levantamento e identificação de espécies de tospovírus em 
Caracterização do Tomato chlorotic spot virus isolado de jiló no...

tomateiro e pimentão no sub-médio do Vale do São Francisco e no Distrito Federal. Summa Phytopathologica 26:205-210. 2000 .

MUMFORD, R.A., BARKER, I. \& WOOD, K.R. An improved method for detection of Tospoviruses using the polymerase chain reaction. Journal of Virological Methods 57:109-115. 1996.

NAGATA, T., DE ÁVILA, A.C., TAVARES, P.C.M., BARBOSA, C.J., JULIATTI, F.C. \& KITAJIMA, E.W. Occurrence of different tospovirus in six States of Brazil. Fitopatologia Brasileira 20:90-95. 1995.

PAGOTO, J.M. Jiló (Solanum gilo Raddi). In: Manual Técnico das Culturas (CATI), Edição Especial. Campinas. Governo do Estado de São Paulo. N. 8. 1986. pp. 254-256.

PETERS, D. An updated list of plant species suscetible to tospoviruses. In: Peters, D. \& Goldbach, R. (Eds.). Recent Progress in Tospovirus and Thrips Research, Wageningen, The Netherlands, 1998. pp.107-110.

POZZER, L., BEZERRA, I.C., KORMELINK, R., PRINS, M., PETERS, D., RESENDE, R.O. \& DE ÁVILA, A.C. Characterization of a Tospovirus isolate of Iris yellow spot virus associated with a disease in onion fields in Brazil. Plant
Disease 83:345-350. 1999.

PRINS, M. \& GOLDBACH, R. The emerging problem of tospovirus infection and nonconventional methods of control. Trends in Microbiology 6:31-35. 1998.

RESENDE, R.O., POZZER L., NAGATA, T., BEZERRA, I.C., LIMA, M.I., KITAJIMA, E.W. \& DE ÁVILA, A.C. New tospoviruses found in Brazil. Proceedings of the International Symposium on Tospovirus and Thrips of Floral and Vegetable Crops. Acta Horticulturae 431:78-89. 1996.

SAMBROOK, J., FRITSCH, E.F. \& MANIATIS, T. Molecular Cloning: A laboratory manual. $2^{\text {nd }}$ ed. New York, Cold Spring Harbor Laboratory Press. 1989.

SANGER, F., NICKLEN, S. \& COULSON, A.R. DNA sequencing with chain terminating inhibitors. Proceedings National Academy of the Science 74:5463-5467. 1977.

VAN REGENMORTEL, M.H.V., FAUQUET, C.M., BISHOP, D.H.L., CARSTENS, E.B., ESTES, M.K., LEMON, S.M., MANILOFF, J., MAYO, M.A., McGEOCH, D.J., PRINGLE, C.R. \& WICKNER, R.B. Virus Taxonomy Classification and Nomenclature of Viruses. Seventh Report of the International Committee on Taxonomy of Viruses. Academic Press, California, USA. 2000. 